\title{
IN-WATS Reference Service at the University of North Carolina Chapel Hill
}

\author{
by G. John Heyer \\ Pennsylvania State University Library
}

The IN-WATS (Inward Wide Area Telephone Service) Reference Service of the North Carolina State Library began operation on February 1, 1968. At first serving a selected group of public libraries, the system has expanded to include all public libraries and those of all two- and fouryear colleges and technical institutes in the state. Agencies of state government and contracting corporate libraries also use the service.

Since early in the history of the system, the State Library has had to call frequently on libraries of the three major universities in the Triangle area (University of North Carolina at Chapel Hill, Duke University, and North Carolina State University) for assistance in filling title and information requests for participating libraries. In September, 1971, a contractual arrangement was established between the State Library and the library of each of these three institutions. These contracts, which are renewed annually, guarantee that the university libraries will provide ondemand reference and interlibrary loan services to the State Library in return for a stated monthly fee. The contracts suggest, but do not require, that each univer- sity library establish one or more positions to provide this service.

In September 1972 the University of North Carolina became the first of the contracting libraries to establish a position (Network Reference Librarian) charged primarily with answering information requests referred by the IN-WATS Reference Service.' The referral service has been closely modeled on the IN-WATS operation at the State Library to which the Network Reference Librarian was assigned for three weeks in September 1972. The new referral service at the University of North Carolina began operation on October 9, 1972. It has dealt only with information requests; requests for specific titles located at the University of North Carolina continue to be sent directly to the Interlibrary Center by the State Library.

Questions are received by telephone from the State Library during its hours of business and are recorded on the same worksheet form used by the State Library IN-WATS section. Information received includes the name of the requesting library, the name of the IN-WATS librarian referring the question, the question, and sources checked by the State Library before re- 
ferring the question to the University of North Carolina. A daily tally is kept to record the number of questions received.

The Network Reference Librarian processes himself nearly all reference questions received. In his absence this work is done by full time staff of the Humanities Division of Wilson Library. The nature of the questions requires frequent consultation with librarians in several departments of the Wilson Library and in outlying libraries on campus. The Network Reference Librarian has visited each of the departmental and divisional libraries and has oriented their librarians to the system.

Some questions are best answered by sending library materials or photocopies directly to the requesting libraries. The original telephone information request is interpreted as an authorization for an interlibrary loan if in the discretion of the Network Reference Librarian such a loan would best answer the question. In this case the Network Reference Librarian locates the book(s) in the Wilson stacks or checks it out from outlying libraries, prepares an interlibrary loan form and takes both to the interlibrary loan office which dispatches the book and keeps records of the loan. In the case of books in the Law and Health Sciences Libraries, which have their own interlibrary loan operations, bibliographic information is dispatched to the State Library, which prepares the form and submits it to the lending library.

The State Library has a policy of not charging for photocopied materials of less than six exposures sent to libraries in connection with the IN-WATS system. To conform with this policy in regard to photocopied materials sent to answer questions referred to Chapel Hill, the State Library has authorized the Network Reference Librarian to bill photocopy orders of less than six exposures to the State Library deposit account in Photographic Services. Larger orders are billed to the requesting library, which has been informed of the estimated cost and has agreed to pay it. The Network Reference Librarian takes the material to be photocopied along with a form also used by the State Library de- scribing what is to be copied, where it is to be sent and who is to be billed to the billing clerk at the Photographic Services section of the Library, who has the copying done and dispatches the material directly to the requesting library.

Reports are made by telephone to the State Library as soon as the information is obtained or the loan or photocopy initiated. The State Library contacts the requesting library and passes on the information.

Questions referred to the contracting institutions frequently went unanswered before the contracts were established. As approximately 75 percent of the questions received at Chapel Hill from IN-WATS at the State Library are answered, the referral service is a significant addition to the whole IN-WATS system. In the first fiscal year the service was in operation (1972-73), 277 questions were received. In the following fiscal year, the number increased to 415. In the calendar year 1973, an aver-

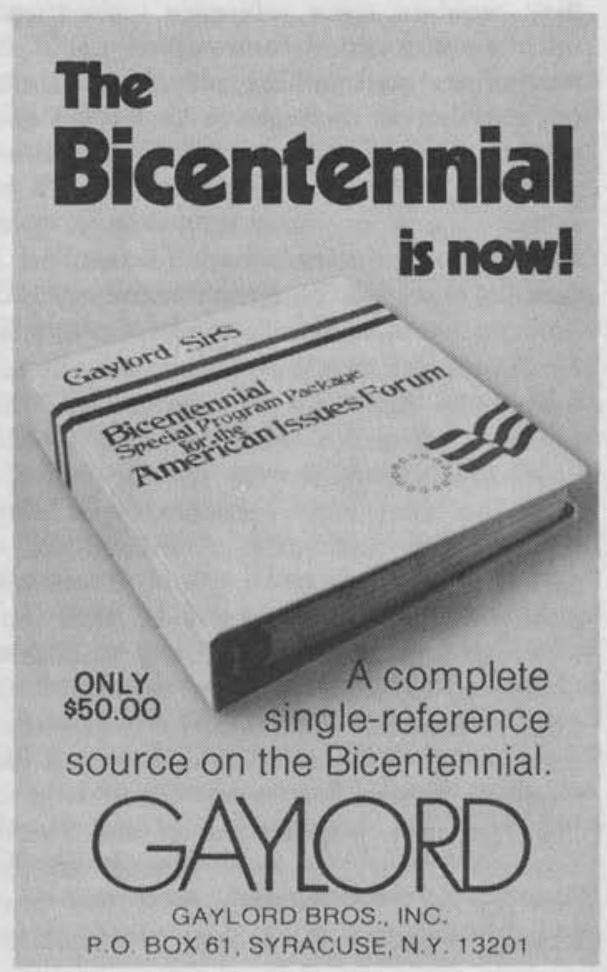


age of 1.85 questions per working day (i.e. a day that both the State Library and the University of North Carolina Library were open) was transmitted by the State Library to the referral service at Chapel Hill.

The diverse nature of questions received at Chapel Hill makes these statistics an inaccurate guide to the workload. Time spent in answering questions ranges from a few minutes to several days, with some questions which are referred to other libraries or require correspondence taking weeks before an answer is received, although the great majority of questions are answered within three days.

An analysis of 495 questions answered by the Chapel Hill referral service between October 9, 1972, and December 31, 1973, indicates that 172 questions are directly related to the interlibrary loan functions of the statewide information network. These questions were transmitted to the Network Reference Librarian rather than to the Interlibrary Center either because they required some reference work to put each request in a form which could be treated as an interlibrary loan or photocopy order, or because a time limit precluded use of the standard interlibrary channels. Of the 172 questions, 45 resulted in one or more books on a given subject being loaned, and 22 resulted in specific materials being photocopied. 105 requests were for locations of specific titles.

The remaining 323 information requests have been classified and appear in Table I. $^{2}$ Most numerous were requests for biographical information on specific individuals. The next most frequent types were requests for addresses of individuals or societies, questions dealing with books and publishing, and questions of the exact wording type. The books and publishing category included reviews and criticism, and verifications of titles for which locations were not requested. Requests for medical information were transferred to the reference department of the Health Sciences Library at their request so that they could work directly with the State Library in finding the proper information.
The questions referred by the State Library to the University Library at Chapel Hill and to the libraries of North Carolina State University and Duke University, although many in number and covering a wide range of subjects, are only a small part of the workload of the statewide information network. The referral system is thus an added dimension for a network which has become an important tool for bringing materials and information to library users throughout North Carolina.

\section{Table I}

Questions Referred To University of North Carolina-Chapel Hill

By The IN-WATS Reference Service

\section{Number of Questions}

Category

Meaning Type 35

Numerical or Statistical Type _... 19

Historical Type

Exact Wording Type _..._ 40

Proper Names 4

Address of Individuals or Societies 44

Books and Publishing _.__ 44

Biography _._ 61

Illustrations _._. 11

Geographical Facts _._. 3

How to Do Type

General Information on a Subject 12

Medical Information _._._. 13

Business Information _._. 11

Information Concerning the

University of North Carolina

TOTAL

\section{Footnotes}

'In April, 1974, a reference librarian at the D. H. Hill Library of North Carolina State University was designated "Interlibrary Reference Librarian" and assigned the primary responsibility for the service at that library.

${ }^{2}$ The classification uses twelve applicable categories from a classification system in Florence $R$. Van Hoesen, An Analysis of Adult Reference Work in Public Libraries As An Approach To The Content of A Reference Course (Ph.D. dissertation, University of Chicago, 1948), pp. 207-216. The last three categories were created to reflect the specialized nature of certain questions received at Chapel Hill. 